\title{
EL CONCEPTO DE LIBERTAD DE CULTOS EN EL DEBATE DE LAS CORTES CONSTITUYENTES DE 1869
}

\section{THE CONCEPT OF CULTS FREEDOM IN THE 1869 CONSTITUTION DEBATE}

\author{
Ana Isabel González Manso \\ Universidad del País Vasco
}

\begin{abstract}
SUMARIO: I. INTRODUCCIÓN. - II. CONTEXTO RELIGIOSO PREVIO A LA APROBACION DE LA LIBERTAD DE CULTOS. - III. PRIMERAS REACCIONES ANTE EL PROYECTO CONSTITUCIONAL.- IV. LIBERTAD DE CULTOS Y DERECHO INDIVIDUAL.- 4.1. Catolicismo y Liberalismo.- 4.2. Moral Universal: La Propuesta Republicana.- V. RELACIONES IGLESIA/ESTADO.- 5.1. Fundamentación Teórica.- 5.2. Formas de Plasmación Política.- VI. LA DISPUTA ENTRE TOLERANCIA E INTOLERANCIA RELIGIOSAS.- VII. CONSECUENCIAS DE LA LIBERTAD RELIGIOSA.- VIII. CONCLUSIÓN.
\end{abstract}

Resumen: La Constitución de 1869, estableció por fin, tras muchos vaivenes constitucionales, la libertad de cultos en España, aunque su grado de aplicación será escaso y su vida muy breve. En este trabajo analizamos qué entendieron por este concepto los diputados y publicistas del momento, su relación con otros conceptos asociados, como libertad de conciencia, tolerancia o religión y consecuentemente qué plasmación política pretendieron y pudieron darle.

Abstract: After some constitutional uncertainties, the 1869' Spanish Constitution established the freedom of cults whose life, however, was very short and its application degree very light. This paper analyses the way by which the Spanish deputies conceived the cult's freedom concept and its relationship with other related concepts such as consciousness freedom, tolerance or religion. This analysis is used to discuss the political and practical consequences of that concept.

Palabras Clave: Libertad de cultos, Religión, Tolerancia, Siglo XIX, Historia Constitucional española.

Key Words: Cults freedom, Religion, Tolerance, Nineteenth Century, Spanish constitutional history.

\section{INTRODUCCIÓN}

Desde la Constitución de 1812 las sucesivas Constituciones españolas del siglo XIX fueron introduciendo cambios con respecto a la libertad religiosa. Si el artículo 12 de aquella no dejaba cabida para el ejercicio de ninguna religión diferente de la católica, al proclamar que "La religión de la Nación española es y será perpetuamente la Católica, Apostólica y Romana, única verdadera. La 
Nación la protege por leyes sabias y justas, y prohíbe el ejercicio de cualquier otra", la de 1837 permitía la presencia de otras prácticas, limitándose a proclamar una confesionalidad meramente sociológica. Así, en su artículo 11 afirmaba: "La Nación se obliga a mantener el culto y los ministros de la Religión Católica que profesan los españoles".

La Constitución de 1845 parece una vuelta a la defensa de la exclusividad católica (confesionalidad doctrinal pero no excluyente de modo explícito) al afirmar en su artículo 11: "La Religión de la Nación española es la Católica, Apostólica y Romana. El Estado se obliga a mantener el culto y sus ministros". Esta confesionalidad no excluyente quedará truncada con la firma del Concordato de 1851 entre el Gobierno español y la Santa Sede, por el cual en su artículo 1 se establecía de nuevo la confesionalidad excluyente: "La religión católica, apostólica, romana, que con exclusión de cualquier otro culto continúa siendo la única de la nación española, se conservará siempre en los dominios de Su Majestad Católica, con todos los derechos y prerrogativas de que debe gozar según la Ley de Dios y lo dispuesto en los sagrados cánones".

Por su parte, la Constitución non nata de 1856, que establecía una confesionalidad sociológica pero con un posible reconocimiento de la libertad de conciencia, habria podido abrir la puerta a nuevas confesiones en España al proclamar su artículo 14: "La Nación se obliga a mantener y proteger el culto y los ministros de la religión católica que profesan los españoles. Pero ningún español o extranjero podrá ser perseguido por sus opiniones o creencias religiosas, mientras no las manifieste por actos contrarios a la religión".

La revolución de Septiembre de 1868, que supuso la caída del régimen de Isabel II, trajo consigo, por primera vez en España, el establecimiento de la libertad de cultos con la Constitución de 1869. Una libertad estrechamente relacionada con la de conciencia, de pensamiento y religiosa, a la vez que se reforzaba con la proclamación de los derechos de asociación y reunión así como por la libertad de enseñanza. Pero el artículo 21 de la Constitución de 1869 (fusión de los artículos 20 y 21 inicialmente propuestos), no recogió una tajante separación entre la Iglesia y el Estado. De hecho se podría considerar más bien una separación imperfecta o incompleta al haber suprimido la confesionalidad recogida en la Constitución del 45 pero al haber conservado el mantenimiento y culto de la Iglesia católica. Se trataba de una solución de término medio inspirada en el sentido práctico de la mayoría de gobierno; solución tibia pero que estableció la corriente intelectual impulsora de un nuevo enfoque ${ }^{1}$.

Esta aproximación inicial, sin embargo, no nos permite apreciar los cambios que provienen de la modificación de los discursos dominantes. Tal y como afirma Francisco Diez de Velasco

"es como si secularización equivaliese, en una especie de modelo evolucionista lineal bastante caricaturesco, a progreso, a madurez y plenitud del sistema social, a perfecta modernidad, camino gradual hacia la meta deseada que, en este caso, seria la total liberación de los modos religiosos de explicar y ordenar lo social y lo cultural"2.

\footnotetext{
1 Abraham Barrero Ortega, La libertad religiosa en España, CEPC, Madrid, 2006, p. 58.

2 Francisco Diez de Velasco, Religiones en España: historia y presente, Akal, Madrid, 2012, p. 220 .
} 
Lo que nos interesa analizar es qué significados dieron los constituyentes y publicistas de 1869 a los diferentes conceptos relacionados con esta libertad: tolerancia, libertad de conciencia... para intentar responder a la pregunta: ¿Era realmente posible establecer una libertad de cultos diferente de la que se estableció? ${ }^{3}$ No partiremos así pues del grupo politico y de sus miembros para llegar al concepto sino que partiendo del concepto observaremos su utilización por los diferentes miembros de los grupos políticos. El periodo histórico analizado es muy concreto, desde el 11 de febrero de 1869, fecha de apertura de las Cortes Constituyentes, hasta el 5 de mayo de 1869, fecha en la que se votaron los artículos 20 y 21 que consagraron la libertad de cultos. Serán utilizadas como fuentes de estudio los Diarios de Sesiones de las Cortes (DSC) ${ }^{4}$ y los principales periódicos de las diferentes tendencias politicas de la época.

\section{CONTEXTO RELIGIOSO PREVIO A LA APROBACIÓN DE LA LIBERTAD DE CULTOS}

Tras la muerte de Fernando VII, en 1833, el paso de una monarquía absoluta a una monarquía liberal no sólo supuso la transformación de la organización política del reino sino también la desaparición de instituciones esenciales para el orden jerárquico del siglo XVIII. La Iglesia tuvo que adaptarse a esta nueva realidad que le supuso la pérdida de la omnipresente función social y cultural que había tenido hasta el momento. A pesar de que la destrucción casi total de las órdenes religiosas masculinas en la década de 1830 afectó a las escuelas regidas por los regulares, las tres leyes fundamentales que rigieron la educación hasta 1868 (la Ley de Educación Primaria, 1838, y las Leyes de Instrucción Pública, 1845-1857) no pretendieron eliminar la religión de las escuelas estatales, al ser considerada piedra angular de la conducta civil y moral. El Concordato de 1851 y la Ley Moyano de 1857 reconocían el derecho general de la Iglesia a supervisar la educación. Entre 1857 y la Revolución de 1868 la Iglesia se esforzó en conseguir un mayor control de la educación ante el miedo de que desde las escuelas estatales se propagasen las ideas secularizadoras. La efimera

3 Tenemos diferentes aproximaciones a la cuestión religiosa, unas específicas del proceso constituyente de 1869, como las realizadas por Pedro Antonio Perlado, La libertad religiosa en las constituyentes del 69, Univ. de Navarra, Pamplona, 1970, o la de Santiago Petschen, Iglesia-Estado un cambio político. Las Constituyentes de 1869, Taurus, Madrid, 1974 y otras más generales sobre determinadas cuestiones como anticlericalismo: Rafael Cruz, (ed.), El anticlericalismo, Marcial Pons, Madrid, 1997, Emilio la Parra López, Manuel Suárez Cortina (eds.), El anticlericalismo español contemporáneo, Biblioteca Nueva, Madrid, 1998 y Manuel Revuelta González, "El anticlericalismo español en el siglo XIX" en Paul Aubert (ed.) Religión y sociedad en España (siglos XIX y XX), Casa de Velázquez, Madrid, 2002, pp. 155-178; sobre libertad de conciencia: José Antonio Souto Paz, Derecho eclesiástico del Estado. El derecho de la libertad de ideas y creencias, Marcial Pons, Madrid, 1992, Dionisio Llamazares Fernández, Derecho de la Libertad de Conciencia. Conciencia, tolerancia y laicidad, Tomo I, Reuters, Pamplona, 2011, pp. 132-146, VVAA, La tolerancia religiosa en la España contemporánea, Mélanges de la Casa de Velázquez T 44 (1), Casa de Velázquez, Madrid, 2014 y la de Abraham Barrero, op. cit.; sobre relaciones Iglesia-Estado o Iglesia-Sociedad: William J. Callahan, Iglesia, poder y sociedad en España, 1750-1874, Nerea, Madrid, 1989 y la de Manuel de Puelles Benitez, Educación e ideología en la España contemporánea, Labor, Barcelona, 1986.

4 Diario de Sesiones de las Cortes Constituyentes, Tomo II y Tomo III, Imprenta J.A. García, Madrid, 1870. 
ley Orovio de 1868 habría supuesto una fuerte intervención de clérigos y de religiosos en la instrucción pública. Pero la Revolución derogó esta ley y a través del Decreto de 21 Octubre 1868 estableció la libertad de enseñanza.

¿Era católica España a la altura de mediados del siglo XIX?, se han preguntado autores como William Callahan. Para este autor, "la iglesia elaboró con éxito, una amalgama de devociones religiosas y técnicas de evangelización que atrajeron a amplios sectores de la población, desde el campesinado a la burguesía urbana"5. La religión "popular", mal tolerada previamente, se introdujo de lleno en la vida de la Iglesia. El impacto triunfal del devocionalismo y de la piedad en la práctica religiosa aumentó la atracción de la Iglesia y el resurgimiento de las misiones, sobre todo a partir de 1851, fue encaminado a luchar contra el indiferentismo. Pero para Callahan entre 1850 y 1900 se fue produciendo un proceso de descristianización ${ }^{6}$. De esta misma opinión es Antonio Moliner Prada, quien afirma que a mediados del siglo XIX se aceleró ese proceso, sobre todo en las grandes ciudades y en las zonas agrarias latifundistas, como consecuencia de la pérdida de influencia de la Iglesia entre las clases populares ${ }^{7}$.

Este proceso de descristianización fue acompañado, al final del reinado de Isabel II, del intento por parte del clero de aumentar su influencia en la esfera del poder civil, tal y como destaca Gregorio de la Fuente Monge: de hecho el clero fue el único baluarte con el que contó la reina desde 1863. Por ello los revolucionarios culparon a Isabel II de haber favorecido los intereses clericales llegando a convertir el régimen liberal en una dictadura teocrática ${ }^{8}$. La Revolución de 1868 ("La Gloriosa”) cuyo lema fue “¡Abajo lo existente!" provocó una fuerte oleada de anticlericalismo, de la que se hizo eco la prensa católica. Pero la violencia anticlerical no fue dirigida contra la fe o las creencias populares sino contra las estructuras eclesiásticas y además el grado varió en cada una de las juntas revolucionarias que se constituyeron ${ }^{9}$. En realidad, tal y como apunta Antonio Moliner, la aplicación de las resoluciones anticlericales dependió en gran parte del talante de los gobernadores civiles y de sus buenas o malas relaciones con los obispos de sus diócesis ${ }^{10}$.

A partir de octubre 1868, el gobierno provisional adoptó una serie de medidas radicales contra la Iglesia ${ }^{11}$ : derogación del fuero eclesiástico, expulsión

5 William J. Callahan, Iglesia, poder y sociedad en España, op. cit, p. 226.

6 Ibidem, p. 234.

7 Antonio Moliner Prada, "Anticlericalismo y revolución liberal (1833-1874) en Emilio la Parra López, Manuel Suárez Cortina (eds.), El anticlericalismo español contemporáneo, op. cit., p. 69-125, p. 103.

8 Gregorio de la Fuente Monge, "El enfrentamiento entre clericales y revolucionarios en torno a 1869", Ayer, 44(2001), pp. 127-150, p. 127.

9 Antonio Moliner Prada, “Anticlericalismo y revolución liberal”, op.cit., p. 107.

10 Ibidem, p. 109.

11 El gobierno provisional de 1868-1871 fue un gobierno transitorio formado tras la Revolución de 1868. En una primera etapa, que es la que comprende este estudio, este gobierno estuvo compuesto por las fuerzas politicas firmantes del Pacto de Ostende y protagonistas de la Gloriosa: el partido progresista encabezado por el general Juan Prim y la Unión Liberal liderada por Francisco Serrano. A estos se añadirán los demócratas monárquicos, los conocidos como 
de los jesuitas, supresión de todas las órdenes religiosas y derribos de edificios religiosos (con fines urbanísticos o sociales, según de la Fuente) ${ }^{12}$. Pero no se produjeron por lo general, ataques contra el clero: "la sacrílega piqueta revolucionaria fue más secularizadora que anticlerical"13. Según este autor, las elites revolucionarias, para evitar una ruptura prematura de la coalición liberal, sólo identificaron como fuente visible de todos los males a Isabel II con lo que salvaron a la Iglesia de convertirse en objetivo prioritario de las protestas populares.

De diferente opinión es Manuel Revuelta para el cual muchas de las medidas anticlericales tomadas por el Gobierno, además de herir los sentimientos católicos, habrian ido en contra del ideario democrático proclamado: así la supresión de la Compañía de Jesús y de los conventos de religiosos se habrian dirigido en contra del derecho de reunión o el cierre de colegios de los jesuitas en contra de la libertad de enseñanza. Por ello considerará que el anticlericalismo del Sexenio habria sido un acicate para un catolicismo dormido, pues se habría manifestado desde posiciones hostiles a la fe y considerado el cristianismo una lacra social ${ }^{14}$. Disentimos completamente de esta opinión, tal y como mostraremos a continuación, pues las medidas anticlericales tomadas no implicaron en la gran mayoría de los casos, un rechazo o un menosprecio de la religión católica.

El hecho es que, a partir de finales de 1868, la Iglesia vio peligrar su principal privilegio, la exclusividad de las manifestaciones religiosas, por lo que empezaron a proliferar escritos colectivos de prelados y feligreses dirigidos al Gobierno y que tuvieron gran difusión gracias a la prensa católica y carlista. Así para Solange Hibbs-Lissorgues, tanto los diputados carlistas y los obispos que intervinieron en los debates parlamentarios (Vicente de Manterola, magistral de Vitoria, Antolín Monescillo, obispo de Jaén, Miguel García Cuesta, cardenalarzobispo de Santiago de Compostela) como los periódicos afines a ambos ( $E l$ Pensamiento Español, La Cruz o La Esperanza), presentaron un mismo tipo de argumentación y de actitud beligerante en su defensa de la unidad católica. Para esta autora, la Iglesia empezará a hacer un uso masivo de la prensa en su afán de control de las mentalidades, pasando de un comportamiento defensivo a una verdadera táctica militante ${ }^{15}$. Entre la prensa que aquí se ha consultado reviste particular interés $\mathrm{La}$ Cruz, revista fundada en Sevilla por León Carbonero y Sol y que empezó a salir en Madrid en 1868 con una periodicidad quincenal. Además de publicar documentos pontificios y pastorales es un ejemplo de la militancia de la prensa católica contrarrevolucionaria que destacará por presentar una visión apocalíptica de la situación de los católicos como consecuencia de la Revolución y de las medidas anticlericales tomadas por el Gobierno provisional.

cimbrios, con líderes como Nicolás Rivero, Cristino Martos o Manuel Becerra, participando en coalición los tres partidos a las elecciones constituyentes de enero 1869, elecciones que ganaron. 132 .

12 Gregorio de la Fuente Monge, “El enfrentamiento entre clericales y revolucionarios”, op.cit., p.

13 Ibidem, p. 136.

14 Manuel Revuelta González, "El anticlericalismo español en el siglo XIX”, op. cit., p. 173.

15 Solange Hibbs-Lissorgues, Iglesia, prensa y sociedad en España (1868-1904), Inst. Juan GilAlbert, Alicante 1995, p. 71. 


\section{PRIMERAS REACCIONES ANTE EL PROYECTO CONSTITUCIONAL}

En un clima de gran intolerancia por parte del clero y en particular del episcopado, con ataques violentos por parte de carlistas (como por ejemplo en Burgos contra el gobernador provincial) junto con muestras de anticlericalismo popular, se inició el debate constituyente, teniendo particular protagonismo la discusión de los artículos dedicados a la Libertad de cultos. Los artículos propuestos decían lo siguiente: "Art. 20. La Nación se obliga a mantener el culto y los ministros de la religión católica."; "Art. 21. El ejercicio público o privado de cualquiera otro culto queda garantido a todos los extranjeros residentes en España, sin más limitaciones que las reglas universales de la moral y del derecho. Si algunos españoles profesaren otra religión que la católica, es aplicable a los mismos todo lo dispuesto en el párrafo anterior." Enseguida se plantearon varios problemas: no se establecía una neta separación de la Iglesia católica y del Estado, pues éste continuaba manteniendo el culto y a sus ministros y la libertad de cultos establecida para los españoles pasaba en segundo lugar frente a la de los extranjeros.

Como reconoció la propia Comisión encargada de la elaboración del Proyecto de Constitución ${ }^{16}$, la cuestión religiosa fue la que más dificultades tuvo en su redacción pues en el fondo, y contrariamente a lo que se podría esperar de un texto constitucional, plasmaba "los sentimientos más íntimos [...] los recuerdos que con mayor cariño se conservan en lo interior de cada alma"17. De hecho los diputados abordaron muy frecuentemente cuestiones de dogma o discutieron más de religión que de la forma política que convenía dar a la religión en España, suscitando numerosas intervenciones del presidente de la Cámara, el demócrata Nicolás $\mathrm{M}^{\mathrm{a}}$ Rivero, o el reproche de periódicos, como el republicano La Igualdad, que llegó a afirmar: “¿Es la Asamblea un púlpito?”18.

La Comisión justificó su redacción basándose en el hecho de que al ser un asunto en el que estaban implicadas las creencias, había que tener cuidado en el momento de plantear reformas y sobre todo reconocer que el paso de una Iglesia dominante, con exclusión de todo otro culto, al de la separación de la Iglesia y del Estado, era tan grande que "es necesario caminar lenta y gradualmente" y teniendo en cuenta "la corriente de las ideas y el progreso de los tiempos"19. Por ello la Comisión planteó los artículos sobre la cuestión religiosa como fruto de un compromiso (de una transacción) entre los diferentes partidos y las diferentes voluntades personales, buscando, tal y como afirmó el diputado progresista Mata, "un término medio entre el régimen de la separación completa del Estado y la Iglesia y el régimen de los Concordatos, para que se busque un sistema nuevo

16 Esta Comisión estuvo formada por: de la Unión Liberal, José de Posada Herrera, Antonio de los Ríos y Rosas, Manuel Silvela, Augusto Ulloa Castañón y el Marqués de la Vega de Armijo; del Partido Progresista, Eugenio Montero Ríos, Salustiano de Olózaga (presidente), Joaquín Aguirre, Pedro Mata y Juan Valera; del Partido Demócrata, Cristino Martos, Segismundo Moret y Prendergast, Manuel Becerra, Carlos Godinez de Paz y Vicente Romero Girón (secretario). Los republicanos federales quedaron excluidos.

17 Comisión, DSC, 30 de marzo de 1869, Apéndice al n. 37, p. 2.

18 "Crónica parlamentaria", La Igualdad, diario republicano, año II, Imprenta de La Igualdad, Madrid, 28 de abril de 1869.

19 Gil Sanz, DSC, 6 de abril de 1869, p. 862. 
adaptable a nuestra situación y a nuestras aspiraciones". Al mismo tiempo este diputado dejaba la puerta abierta a nuevas redacciones, si las condiciones del país cambiaban en el tema religioso, a través de cambios constitucionales: "¿por ventura, señores, la Constitución presente ha de ser una Constitución eterna?"20.

Pero esta moderación en el planteamiento de la cuestión religiosa no gustó demasiado a la prensa afín y no afin. Así, el periódico progresista La Iberia, aún estando a favor del proyecto constitucional, le reprochará la forma de aquellos artículos en los que "se deja notar la irresolución y el miedo"21. Además considerará que, frente a temas más acuciantes como el vacío del trono, no deberian perder los diputados tanto tiempo en la discusión de la cuestión religiosa. Más contundente y critico será el periódico republicano La Igualdad con respecto a la moderación de los artículos a aprobar: "Preciosa declaración que muestra la incertidumbre, la vacilación de esos hombres de estrecho y mezquino criterio, que inspirándose en las impu()as fuentes del reaccionarismo, temen conformar sus actos a las liberales reclamaciones de la civilización moderna" 22 .

A lo largo del debate se fueron presentando las exposiciones a favor de la unidad religiosa, promovidas desde la Iglesia y prensa afin. De hecho, en diciembre de 1868 un grupo de laicos católicos notables había creado la Agrupación Católica Monárquica, que mutaría al nombre de Asociación de Católicos Españoles (inicio de los movimientos y asociaciones católicas) ${ }^{23}$. Esta Asociación (presidida por el marqués de Viluma), a lo largo de los meses de debates, fue recogiendo firmas a favor de la unidad católica, llegando a 2.837.144, que presentará el obispo de Jaén en las Cortes el 6 de abril de 1869. Con insistencia afirmarán que los artículos propuestos no recogían el sentir católico de la Nación y respondian más bien a intereses egoístas de los partidos ${ }^{24}$.

\section{LIBERTAD DE CULTOS Y DERECHO INDIVIDUAL}

Los artículos 20 y 21 propuestos por la Comisión establecían la libertad de cultos. ¿Pero qué entendieron por este concepto los diferentes partidos y otros actores políticos? Exceptuando a los carlistas y al clero, para la mayoría de los diputados de la Cámara esta libertad se englobaría dentro de los derechos individuales del hombre.

Manterola culpaba a Hegel de que el hombre pretendiese sustituir a Dios al querer ser el origen de una serie de derechos naturales, cuando en realidad sólo la religión católica era la ley natural emanada de los Evangelios ${ }^{25}$. Además, tal y como expuso el diputado carlista Díaz Caneja, la libertad de cultos no podía ser

20 Mata, DSC, 3 de mayo de 1869, p. 1575.

21 "Política: Proyecto de Constitución", La Iberia, periódico liberal, año XVII, Imprenta de La Iberia, Madrid, 2 de abril de 1869.

22 "El proyecto constitucional", La Igualdad, 1 de abril de 1869.

23 José Manuel Cuenca Toribio, Catolicismo social y político en la España contemporánea (18702000), Unión Editorial, Madrid, 2003, p.18.

24 “A las Cortes Constituyentes", El Pensamiento Español, diario católico, apostólico, romano, año X, Imprenta Pelayo 34, Madrid, 3 de abril de 1869.

25 Manterola, DSC, 12 de abril de 1869, p. 978. 
un derecho individual, al ser los cultos diferentes al católico frutos de falsas revelaciones. Este diputado sí admitió la libertad de conciencia, diferenciándola de la libertad de cultos, al restringir el culto al área privada ${ }^{26}$.

Posición totalmente diferente fue la que mantuvo el resto de los diputados de la Cámara, con independencia del grupo político al que pertenecían, aunque se aprecian matices.

El diputado de la Unión Liberal Cirilo Álvarez aprovechará la definición de derechos individuales para defender la interpretación liberal de los mismos frente a la doctrinaria y la radical: dicha interpretación liberal supondría el justo medio que permitiría la defensa de las libertades, pero en un marco de orden y acorde al estado de la Nación frente a la radical que negaría el derecho de represión contra los abusos y desmanes que se pudiesen cometer en su ejercicio o la doctrinaria que "asustada por la libertad misma", establecía tales limitaciones que la libertad terminaba por desaparecer ${ }^{27}$.

Para la mayoría de estos diputados, la libertad de conciencia implicaría la libertad de pensamiento y la libertad de cultos. Esta última no podría entenderse como tolerancia de cultos pues éstos habrian de poder manifestarse públicamente 28 .

El Imparcial, considerado como el periódico más influyente en España en el último tercio del siglo XIX y afín a la Unión Liberal, dedicará varios números a la cuestión religiosa. En ellos establecerá una igualdad de significados entre libertad de cultos y libertad religiosa puesto que al hablar de ésta "sólo puede hacerse referencia a las religiones positivas, a las religiones con culto"29. Pero establecerá una diferencia entre libertad de cultos y libertad de conciencia, poniendo como ejemplo las diferentes Constituciones vigentes en diferentes países, en las cuales se permitía el culto privado pero no el público.

Para el periódico republicano La Igualdad, la libertad de cultos sería un derecho natural consecuencia ineludible de la libertad de conciencia ${ }^{30}$. Aunque para el diputado republicano Palanca la libertad de cultos se englobaría dentro de los derechos individuales, la conclusión final a la que llegan él y la mayoría de los miembros de su partido, es que ese derecho, para que exista realmente, debe de traducirse en una total separación de la Iglesia y del Estado, pues "los derechos individuales se ejercen siempre; son preexistentes a toda legislación, a todo Estado" no dependen de las condiciones de la sociedad ${ }^{31}$. Esto permitiria exigir la máxima expresión de este derecho sin tener en cuenta la situación real del país.

Por ello Pi y Margall considerará que partir de la preexistencia de una casi unidad católica en España, como afirmaban los miembros de la Comisión, no permitiria alcanzar una "verdadera" libertad de cultos por no ser posible una "verdadera" libertad de pensamiento: “¿es posible que el pensamiento sea libre

\footnotetext{
26 Díaz Caneja, DSC, 4 de mayo de 1869, p. 1618.

27 Álvarez (Cirilo), DSC, 22 abril de 1869, p. 1283.

${ }^{28}$ Mata, DSC, 7 de abril de 1869, p. 884.

29 "La cuestión religiosa I", El Imparcial, diario liberal, Imprenta de El Imparcial, Madrid, 28 de marzo de 1869.

30 "La libertad de cultos es de derecho natural I", La Igualdad, 16 de abril de 1869.

31 Palanca, DSC, 22 abril de 1869, p. 1277.
} 
dentro de la unidad católica? El pensamiento no puede manifestarse, no puede desenvolverse sin dar contra esas paredes de hierro creadas por el catolicismo; no es posible que el pensamiento sea libre dada la unidad religiosa" por ello abogará por la total separación Iglesia-Estado ${ }^{32}$.

\subsection{Catolicismo y Liberalismo}

Desde los debates de la Constitución de Cádiz los detractores del liberalismo consideraron que cualquier intento de reformar la Iglesia equivalia a su exterminio. Por ello, desde la tribuna de las Cortes o desde las páginas de los periódicos, arremetieron contra los liberales de toda clase y condición. En las Cortes de 1869, Manterola llegó incluso a acusar al liberalismo de ser hijo de Satanás. En palabras de Manterola:

"Si por liberalismo había de entenderse la emancipación completa del hombre de su Dios; si por liberalismo había de entenderse la exageración de sus derechos individuales, la exageración de la libertad humana hasta el punto de establecer un antagonismo horrible entre Dios y el hombre, si el liberalismo había de significar el acto de escalar el hombre los cielos y destronar a Dios, entonces el autor del liberalismo es el mismo Satanás"33.

No olvidemos que la publicación del Syllabus en 1864 por parte de Pio IX, había supuesto una condena expresa del liberalismo.

Los carlistas y buena parte del clero atacarán de manera furibunda a los diputados partidarios de los artículos "librecultistas", llegando a afirmar "¿Y esto lo proponen diputados que se dicen católicos?”. Para ellos, defender la libertad de cultos implicaba inexorablemente no ser católico y querer acabar con la Iglesia católica $^{34}$. Nos encontramos con las mismas críticas que sufrieron los primeros liberales al aprobar la Constitución gaditana. Así, en 1812, desde las páginas del periódico El Procurador General de la Nación y del Rey, calificaban al liberalismo de "ese monstruoso Dragón de la secta francmasónica que reúne la astucia y delirios de los herejes antiguos y modernos"35. Además, para Manterola, la Libertad sólo podría ejercerse en el marco estricto del catolicismo: "lo que quiere la Iglesia católica es que el ejercicio de la libertad esté siempre dentro, y sólo dentro del círculo de lo justo, de lo honesto y de lo lícito"36. Incluso para $E l$ Pensamiento el Gobierno se convertiria en tirano al querer legislar sobre lo que no tenía derecho alguno, colocándose en lugar de la Iglesia y los hombres en lugar de Dios ${ }^{37}$.

32 Pi y Margall, DSC, 3 de mayo de 1869, p.1566.

33 Manterola, DSC, 12 de abril de 1869, p. 978.

34 "La cuestión religiosa", El Pensamiento, 22 de abril de 1869.

35 Ana Isabel González Manso, “Tolerancia religiosa y modelo de Iglesia en España en la primera mitad del siglo XIX", Historia Constitucional, n. $15, \quad 2014$. http://www.historiaconstitucional.com, págs. 113-153, p.122.

36 Manterola, DSC, 26 de abril de 1869, p. 1368.

37 "La Tiranía y el despotismo en Religión", El Pensamiento, 29 de marzo de 1869. 
Para la mayor parte de los liberales e incluso de los republicanos, libertad y cristianismo, no estaban reñidos. De hecho, con frecuencia se argumentó que la libertad religiosa se deducía directamente de los Evangelios:

\begin{abstract}
"Somos liberales, porque somos católicos; somos católicos, porque creemos que sólo a la sombra de la libertad pueden saborearse los beneficios de una religión de caridad y amor [...] ambas prácticas se hermanan perfectamente, porque de una misma fuente proceden, porque su misión es la de instruir, educar, en una palabra, civilizar al pueblo"38.
\end{abstract}

$Y$ es en nombre de ese catolicismo que estos diputados proclamarán la libertad de cultos. El problema para muchos de ellos era la Iglesia católica en cuanto institución; por ello, y al igual que hicieron los primeros liberales en los inicios de siglo XIX y la mayor parte de los demócratas a mediados de ese siglo, muchos de estos diputados recurrirán a la reivindicación de la Iglesia primitiva, adalid de valores liberales y democráticos frente a la actual Iglesia corrupta por su afán de poder y dinero e interesada sólo en los intereses terrenales ${ }^{39}$.

Esta crítica a la Iglesia como institución fue más intensa desde el bando republicano, católico o no. Así para diputados como Castelar, la Iglesia católica habria sido y era totalmente opuesta a los principios del liberalismo, se plasmasen éstos de manera más o menos moderada en las diferentes Constituciones. Para este diputado, la Iglesia no habría perdonado las Constituciones liberales y su lucha, en el fondo, sería contra el liberalismo:

\begin{abstract}
"Notad, Sres. Diputados, notad bien: la Iglesia no nos ha perdonado, la Iglesia no nos perdonará nunca todo cuanto hemos hecho a favor del pueblo español. En vano los hombres de 1812 escribieron aquel artículo que entregaba nuestra conciencia al catolicismo; en vano los hombres de 1837 hicieron lo mismo, y si lo modificaron, lo modificaron ligeramente. En vano en 1856 tuvimos una complacencia servil con la tolerancia religiosa; siempre en vano. Vivimos, nos desarrollamos, morimos bajo los anatemas de la Iglesia, que no quiere nada con nuestra política"40.
\end{abstract}

Para este diputado, por culpa de la Iglesia como institución, el catolicismo habría sido y era contrario a todo lo que significase progreso en todas las facetas de la vida: "No hay un principio, absolutamente ninguno, que constituya la ciencia, aunque sea la base del derecho moderno, que no haya sido maldecido por la Iglesia católica". Para Castelar, la Iglesia se habría opuesto a todo avance científico, filosófico o político, base del desarrollo de las sociedades modernas ${ }^{41}$.

\title{
4.2. Moral Universal: La Propuesta Republicana
}

Uno de los conceptos que compitió con el de religión fue el de moral universal. Este concepto será defendido en algunos casos como sustitutivo y en otros como complementario al de religión. La moral serviría de contrapeso para moderar los posibles desmanes sociales a falta de una religión. Ante los

\footnotetext{
38 "Politica", La Iberia, 5 de mayo de 1869.

39 Gil Sanz, DSC, 6 de abril de 1869, pp. 860-61.

40 Castelar, DSC, 7 de abril de 1869, p. 900.

41 Ibidem, p. 899.
} 
problemas que planteaba el catolicismo por culpa de sus aspectos institucionales, los republicanos, principalmente, abogarán por dar un mayor protagonismo a la moral universal como elemento regulador de las sociedades.

Para los carlistas y buena parte del clero, pretender sustituir la religión católica por el freno de la moral universal era un peligro pues "no son regla segura, porque la moral universal, independiente de la idea religiosa, es una utopia" y "la moral se asienta en la religión" 42.

Los liberales católicos pondrán en cambio el acento, en clave ilustrada, en que sólo las personas instruidas podrian alcanzar el concepto de moral, pero el pueblo no; para éste sólo quedaría la moral católica ${ }^{43}$. Y la moral, católica o no, era imprescindible para mantener el orden social.

Visión totalmente diferente tendrán los republicanos quienes reivindicarán un papel más importante de la moral en el tejido constitucional. Para Castelar, moral y religión, además de actuar a través de la razón, tendrían las mismas funciones y aportarian las mismas soluciones a los problemas del ser humano, incluso en fin de vida: "¿Y qué hace la religión? Lo mismo que hace la moral [...] y al acercarnos a la última hora, al acercarnos al abismo de la eternidad, sostenernos y consolarnos..."44. Pero para este diputado, ante la situación de indiferentismo al que habría llevado a la sociedad la Iglesia católica, sólo la moral universal podría salvar al mundo del estado de crisis en el que se encontraba: "Esta grande crisis, esta crisis moral sería espantosa si no tuviéramos un principio [...] (por el cual) todos los hombres practiquen los principios de eterna moral que están grabados en el fondo de la conciencia humana"45. Incluso para Suñer la condición de ateo no equivalia a carecer de moral. Una moral, eso sí, humana, racional:

"Es un error, y un error grande, el creer que los materialistas estamos reñidos con la moral: somos morales, queremos la moral, y el último fin de nuestras predicaciones es la moral, pero la moral independiente, la moral humana y nacida del corazón humano, no la que nace de la noción de Dios"46.

Por ello compartimos la opinión de José Álvarez Junco sobre las dosis de moralidad y de actitudes cristianas de los anticlericales, frente a la de Revuelta González, quien relaciona los niveles de anticlericalismo con el ateísmo ${ }^{47}$. Es importante recordar que anticlericalismo no significa irreligiosidad.

42 “Cortes Constituyentes", El Pensamiento, 14 de abril de 1869.

43 Ulloa, DSC, 26 de abril de 1869, p. 1372.

44 Castelar, DSC, 5 de mayo de 1869, pp. 1640-41.

45 Castelar, DSC, 7 de abril de 1869, p. 900.

46 Suñer, DSC, 4 de mayo de 1869, p. 1598.

47 José Álvarez Junco, "El anticlericalismo en el movimiento obrero" en VV.AA., Octubre 1934: cincuenta años para la reflexión, Siglo XXI, Madrid, 1985, pp. 283-300, p. 284; Manuel Revuelta González, El anticlericalismo español en sus documentos, Ariel, Barcelona, 1999, pp.12-13. 


\section{RELACIONES IGLESIA/ESTADO}

\subsection{Fundamentación Teórica}

Para explicar qué tipo de libertad de cultos se pretendia establecer en España, El Imparcial analizó la situación de este derecho en las Constituciones europeas y americanas lo que le llevará a establecer tres grados en la Libertad de cultos:

- Grado uno48: un culto reconocido por el Estado, pero consignando el libre ejercicio de los demás (o dicho de otra forma, Iglesia nacional única subvencionada, sin perjuicio de garantizar el libre y público ejercicio de los demás cultos). Para este periódico, habría dos Constituciones teóricamente incluidas en esta categoria, pero que establecian restricciones: la Constitución federal de Suiza, que en su artículo 44 garantizaba el libre ejercicio, pero sólo a las "comuniones cristianas", y la Constitución de Italia, que disponía que los cultos no establecidos al promulgarse la Constitución, no podrían practicarse en público, y concedía sólo tolerancia, no consignando la libertad religiosa como un derecho del ciudadano. El concepto de tolerancia por si solo excluía para muchos intelectuales el concepto de libertad religiosa. Por su parte, la Constitución de Venezuela, en el párrafo décimo tercero del artículo 14, garantizaba la libertad religiosa, pero sólo la religión católica tendría culto público fuera de los templos.

Para este periódico había otras legislaciones que regulaban el culto público dentro y fuera de los templos y que no imponían restricciones como las previamente consideradas por lo que sería más correcto incluirlas dentro de este primer grado de libertad de cultos. Así ocurría con las Constituciones prusiana y danesa. Ambas sólo ponían como limite que el ejercicio del culto o de las creencias respectivas no sirviese de excusa para incumplir los deberes civiles y políticos de la nación.

Ya en el análisis de este primer grado de la libertad de cultos, el periódico introdujo uno de los factores que suscitará numerosas controversias durante el debate parlamentario, la financiación de los cultos reconocidos: "el ciudadano que no pertenezca a la comunión religiosa pagada por el Estado, tiene, sin embargo, que contribuir con el impuesto al mantenimiento de una Iglesia que no es la suya, y además contribuir al pago del culto a que pertenece".

- Grado dos49: Todos los cultos reconocidos son subvencionados por el Estado. De esta manera, el Estado pagaría el manteniendo del culto y de sus ministros de todos las religiones que considera tienen derecho a ello:

\footnotetext{
"esto es, de todos aquellos que presentando un cierto número de fieles, contribuyentes por los impuestos, y en proporción bastante para que los impuestos que pagan tengan cierta importancia, tienen derecho a reclamar del Estado un servicio en proporción con las contribuciones que satisfacen".
}

Ejemplo de ello sería Francia: este país, que tendría la igualdad de cultos, sólo habría reconocido con este objeto, el católico, los protestantes (reformado y

48 "La cuestión religiosa II", El Imparcial, 30 de marzo de 1869.

49 “La cuestión religiosa III", El Imparcial, 1 de abril de 1869. 
luterano) y el israelita pero todas las demás comuniones religiosas podian libremente practicar su culto respectivo. En este caso, para el articulista del periódico se respetaba mejor el principio de justicia "pero aun se conserva el criterio de que el Estado intervenga en la cuestión religiosa". Con respecto a Inglaterra el articulista considera que alli habría una "legislación mixta que no es ni el primero ni el segundo grado de la libertad de cultos, ni tampoco la separación de la Iglesia y del Estado. Hay una Iglesia oficial reconocida, pero no subvencionada por el Estado".

\section{- Grado tres ${ }^{50}$ :}

"Con la separación de la Iglesia y el Estado, éste no legisla en modo alguno ni sobre la existencia de tales o cuales comuniones religiosas, ni sobre la mayor o menor subvención que a una de ellas o a varias convenga dar, ni sobre punto alguno que con la cuestión religiosa, y bajo el punto de vista de religión y de culto, pueda rozarse".

Los fieles contribuirian al mantenimiento de su culto y tomarian las decisiones correspondientes a su religión. Para el articulista, este grado de libertad de cultos sólo existiría en Estados Unidos, en donde se estaría poniendo en práctica la total separación de la Iglesia y del Estado: en virtud de la primera enmienda a la Constitución "el Congreso no hará ley alguna que tenga por objeto el establecimiento de ninguna religión, ni la prohibición del libre ejercicio de cualquiera de ellas". Con esta redacción clara y breve, el Estado renunciaba a intervenir en la cuestión religiosa. Según el articulista, en las demás naciones europeas o americanas sólo existiría el primer o el segundo grado de la libertad de cultos. Asimismo destacará, con una intención partidista, que las Constituciones monárquicas de Holanda, Bélgica, Prusia... eran más liberales, en cuanto a la libertad religiosa, que las Constituciones de repúblicas (unitarias o federales) como Suiza, Chile, Ecuador, la Confederación Argentina, Bolivia o Venezuela.

Después de este análisis detallado, el articulista concluirá que los artículos propuestos para la Constitución española sólo recogerian el primer grado de la libertad de cultos achacando esta limitación al miedo de la Comisión (como ella misma reconocía, según hemos visto) a una transición muy brusca de la intolerancia a una verdadera separación Iglesia-Estado. Este periódico recogerá además la opinión de otro diario, La Nación de tendencia progresista, que señalaba que esta libertad de cultos limitada planteaba dos problemas: uno político, al no satisfacer las aspiraciones de muchos liberales, y al ser al mismo tiempo demasiado avanzada para otros sectores de la población; y otro económico, al hacer pagar doblemente a los no católicos ${ }^{51}$.

Castelar hará una división más escueta e ideológica de las posibles relaciones entre Iglesia y Estado. A su juicio, estas relaciones sólo podian ser conflictivas:

"O la Iglesia predomina sobre el Estado, lo cual crea la forma teocrática [...], o el Estado predomina sobre la Iglesia, lo cual trae la autocracia [...] o la Iglesia establece

50 "La cuestión religiosa IV", El Imparcial, 2 de abril de 1869.

51 "Declaraciones", El Imparcial, 29 de marzo de 1869. 
relaciones por los Concordatos que [...] producen la infinidad de dificultades y obstáculos que tienen los contratos con la Iglesia"52.

La unión entre ambas entidades se habría mantenido y se pretendía mantener por cuestiones de miedo a la alteración del orden ("Los hombres de Estado en su mayor parte no creen, y pagan a la Iglesia y sostienen a la Iglesia solamente como un elemento de conservación del orden") pero supondrian un agravio económico para los no católicos. Además, para este diputado no podía existir una Iglesia Nacional subvencionada (como establecería el primer grado de la libertad de cultos que se quería aprobar) pues el Estado no podia tener una religión y el creer o no, sería una cuestión personal ${ }^{53}$. La religión vista como un asunto privado es la clave para entender la postura de la mayor parte de los republicanos, católicos o no, ante la libertad de cultos.

El también diputado republicano Pi y Margall planteará la discusión en términos de coexistencia de poder temporal/poder espiritual. Para este diputado ambos poderes serian complementarios y necesarios, pudiendo coexistir siempre y cuando el poder espiritual fuese totalmente independiente del temporal. No excluirá la necesidad de la religión en la vida de las sociedades, al contrario, la considerará necesaria por ser la única fuente de moralidad para el pueblo no ilustrado:

\begin{abstract}
"E1 poder temporal representa la práctica, y el poder espiritual la teoria; [...] Generalmente, los poderes temporales no ven más que los intereses del momento, los intereses movedizos; se atienen siempre a las circunstancias de lugar y tiempo, al paso que el poder espiritual puede realmente atender a los intereses permanentes, a los intereses universales, a los intereses humanitarios. El poder temporal, además, suele guiarse por la razón de Estado, y a esa razón de Estado sacrifica muchas veces la justicia: el poder espiritual sirve para ir recordando que la razón de Estado es una violación de justicia, y hay necesidad de sobreponer la justicia a esa mal llamada razón de Estado. En ese sentido, el poder temporal y el poder espiritual pueden ser útiles el uno al otro; pero ¿con qué condiciones? Con la condición de que el poder espiritual sea un poder que represente la suma ilustración, la suma ciencia, con la condición de que esté a la cabeza de la civilización de nuestros tiempos y sea sobre todo un poder independiente" 54 .
\end{abstract}

El problema con la Iglesia católica, según Pi, es que ésta había pretendido dominar la esfera espiritual y la terrenal, contraviniendo sus principios fundacionales ${ }^{55}$.

Una interpretación totalmente diferente hará el Obispo de Santiago, García Cuesta, de la coexistencia de las dos potestades: él también planteará la distinción Iglesia/Estado en término de potestades pero supeditando la temporal a la espiritual ${ }^{56}$; no hay así pues grandes diferencias frente a lo que había defendido la Iglesia del Antiguo Régimen.

52 Castelar, DSC, 7 abril de 1869, p. 901.

53 Castelar, DSC, 12 de abril de 1869, pp. 987-988.

54 Pi y Margall, DSC, 3 de mayo de 1869, p. 1570.

55 Sorní, DSC, 30 de abril de 1869, p. 1497.

56 García Cuesta, DSC, 28 de abril de 1869, p. 1429. 


\title{
5.2. Formas de Plasmación Politica
}

Como hemos visto hasta el momento, tres van a ser las principales posibilidades barajadas por los políticos del momento: mantener la confesionalidad católica del Estado, establecer la separación Iglesia/Estado y acomodarse a las exigencias de la realidad sociológica española y al espíritu de transacción.

Al clero la idea de separar Iglesia y Estado le horrorizaba, sería como separarse de Dios. Para él, el Estado tenía la obligación de apoyar a la Iglesia y de seguir sus directrices: es decir de subordinarse a ella, tal y como hemos visto en el apartado anterior. Los argumentos en los que basaron su defensa de la confesionalidad del Estado se podrian reducir a tres: la religión católica es la verdadera, es lo que desea el pueblo español y es la única manera de mantener el orden moral y social.

Los carlistas y buena parte del clero, al defender que se mantuviese la unidad religiosa con un solo culto, el católico, reconocido por el Estado, considerarán que los artículos propuestos por la Comisión, a pesar del mantenimiento de culto y clero, no garantizaban esas premisas. Así para el Obispo de Santiago:

\begin{abstract}
"A la verdad se le debe más protección que al error, y siendo la religión católica la verdadera, merece más protección que las religiones falsas. Estas sólo deben aspirar a que no se las moleste, a que no se las atropelle en sus ceremonias religiosas; pero la religión verdadera debe exigir algo más del Estado, debe exigir una protección más especial" ${ }^{2}$.
\end{abstract}

Para Manterola, aunque el Estado se comprometiese a mantener el culto no significaría que estuviese convirtiendo el catolicismo en religión de Estado, que es lo que él defiende: "según la redacción de este artículo, el Estado en España no tiene religión, no cree en Dios"58. Además para Ortiz de Zárate el pago del culto y de sus ministros sería sólo la indemnización a la cual la Iglesia tendría derecho tras las amortizaciones realizadas en las décadas anteriores ${ }^{59}$.

Al ir avanzando el debate y considerar inevitable la aprobación de los artículos "librecultistas", parte de los diputados carlistas abogarán por un concepto sui generis de libertad religiosa: la liberación de la Iglesia de las regalias $^{60}$. Ya desde las páginas de El Pensamiento se había advertido de las limitaciones que supondría para la Iglesia la aprobación de los artículos si se seguía manteniendo el derecho de regalia:

"Los extranjeros y los malos españoles podrán publicar toda clase de blasfemias y calumnias contra la religión en libros, folletos [...] pero tus obispos no podrán publicar pastoral alguna que no pase por la inquisitorial férula del Gobierno que les paga; ni reunirse en concilio sin permiso de su protector, ni dar curso a las Bulas del Sumo Pontífice" 61.

\footnotetext{
57 Ibidem, p. 1431.

58 Manterola, DSC, 12 de abril de 1869, p. 982.

59 Ortiz, DSC, 28 de abril de 1869, p. 1437.

60 Estrada, DSC, 30 de abril de 1869, p. 1490.

61 "La verdad desnuda", El Pensamiento, 5 de abril de 1869.
} 
Es decir, el clero quedaría como un funcionariado público a expensas de las decisiones del Gobierno de turno, que según este periódico podría, bajo pretexto de necesidades económicas, suprimir diócesis, parroquias o incautarse de los bienes de la Iglesia "que para eso les paga". Los republicanos se mostraron completamente partidarios de abolir las regalias, mientras que la Comisión se posicionará a favor de mantenerlas como una táctica frente al clero y como contrapartida a la financiación de los gastos de culto y clero (aunque en su mayoria fuesen contrarios a las regalias) ${ }^{62}$.

Para el resto de los políticos unionistas, progresistas, demócratas y republicanos, la plasmación de las relaciones Iglesia/Estado se podría prospectar bajo dos grandes formas: los que defendieron la posición tomada por el Gobierno (entre los que se contaban unionistas, progresistas y demócratas) de poner en práctica una Libertad de cultos limitada y los que defendieron una puesta en práctica total, es decir la separación total Iglesia/Estado. Los argumentos para defender una u otra de estas posturas matizan el concepto de Libertad de cultos.

Para diputados de la UL como Valera o Ulloa, las religiones, aparte de ser necesarias, eran hechos sociales y para ejercer su función debían estar unidas al Estado. Esa unión no implicaría que el Estado se supeditase a la Iglesia, sino que justificaría mantener el culto y sus ministros ${ }^{63}$ : es una tesis diferente de la defendida por el clero. Incluso la tesis de Cánovas, con una posición más conservadora dentro de la UL, no coincidiría con la desarrollada por el clero para defender el mantenimiento de la Iglesia por parte del Estado. Para este diputado, la Constitución, tal y como se estaba proponiendo en muchos de sus artículos, no estaría garantizando las libertades individuales, entendidas éstas en clave de un total individualismo64. De aquí su opinión con respecto a los artículos sobre la Libertad de cultos:

\footnotetext{
"Se ha legislado de más sobre este derecho individual, puesto que se ha legislado en futuro y para españoles futuros [...] yo no temo afirmar que, no habiendo más religión que la católica en España, el Estado debe proteger, y proteger eficazmente, aunque por medios liberales y legítimos el culto católico"65.
}

De hecho para periódicos como La Iberia, liberal progresista, el defender posiciones muy extremas iría en contra de la mayoría de los españoles que se reconocian católicos y daría armas a los que querían acabar con el liberalismo ${ }^{66}$. Por ello diputados de la UL como Méndez de Vigo o demócratas como Moret considerarán que cambios no acordes con la realidad del país podrían afectar a las creencias del pueblo, pues éste no sabría convivir con ese grado de libertad religiosa, no la entendería, aunque quizá sí podría hacerlo en el futuro ${ }^{67}$. Aparte

\footnotetext{
62 Santiago Petschen, Iglesia-Estado un cambio politico, op. cit., pp. 342-343.

63 Valera, DSC, 29 de abril de 1869, p. 1477; Ulloa, DSC, 26 de abril de 1869, p. 1372.

64 Cánovas, DSC, 8 de abril de 1869, p. 928.

65 Ibidem, p. 935.

66 "Politica", La Iberia, 5 de mayo de 1869.

67 Méndez de Vigo, DSC, 29 de abril de 1869, p. 1464; Moret, DSC, 26 de abril de 1869, p.
} 1377 . 
el siempre presente afán proteccionista de la elite intelectual con respecto al pueblo, podemos observar cómo, para estos diputados, la religión es un elemento fundamental en la vida de las personas pero también en la organización de las sociedades por lo que la libertad de cultos debía reglarse a las características religiosa y social del país. ¿Tactismo político, miedo a reacciones violentas del elemento neocatólico o el argumento de unos artículos adaptados a la realidad del país es una justificación a posteriori del deseo de no romper con la Iglesia? Posiblemente según la forma de entender la creencia religiosa por parte de cada cual, la argumentación podría entenderse de una forma u otra.

Otro de los argumentos del Gobierno para presentar los artículos referentes a la libertad de cultos fue la de equipararse con el resto de países del entorno y atraer a los extranjeros (y así a sus inversiones). Observamos una notable unidad entre progresistas, demócratas e incluso unionistas, pese a la opinión de algunos autores, a la hora de enfocar los problemas politicos y la cuestión religiosa bajo un prisma de sentido empírico ${ }^{68}$. Así, para algunos diputados como Méndez de Vigo, en lo tocante a la convergencia con los demás países europeos, era preciso tener muy en cuenta el punto del que se partía en España y la realidad de los países con los que se pretendia converger: “¿por qué hemos de empeñarnos en tener leyes más adelantadas que ellos?"69. Según Ulloa, un mayor grado de libertad de cultos sólo se había establecido en países donde ya preexistian varios, hecho éste que habria obligado a los gobiernos de esos países a una toma de decisión al respecto. Por ello, el hecho reconocido por la mayor parte los diputados, de que los españoles profesaban en su inmensa mayoría la religión católica, no exigiría una libertad de cultos amplia, pero sí el establecerla ${ }^{70}$.

Para los republicanos, con la salvedad de algunas declaraciones ateístas y partidarias de que en España no hubiese religión alguna (postura defendida principalmente por Suñer) ${ }^{71}$, la libertad de cultos habría de ser total y debería suponer el respeto de todas las religiones. Tres serian las razones aducidas por los republicanos para separar Iglesia y Estado: un principio de justicia, que la separación enriquecería a la Iglesia y evitaría su corrupción y cortar de raíz la influencia eclesiástica sobre el Estado.

La existencia misma de un privilegio a una de las Iglesias estaría invalidando una verdadera libertad de cultos. Así para Figueras: "Nosotros creemos que la justicia tiene dos pies o dos bases, la libertad y la igualdad; careciendo de una o de otra cosa, la justicia es coja, y por consiguiente anda mal. Al conceder un privilegio al catolicismo destruís esta igualdad, $\mathrm{y}$ no hay por consecuencia verdadera libertad de cultos"72.

Además, para Pi y Margall, al privilegiar a la Iglesia católica se le estaría permitiendo que siguiese ejerciendo una influencia sobre el Estado, lo cual podría invalidar incluso la libertad de pensamiento:

68 Santiago Petschen, Iglesia-Estado un cambio politico, op. cit., p. 296.

69 Méndez de Vigo, DSC, 29 abril de 1869, p. 1467.

70 Ulloa, DSC, 26 de abril de 1869, p. 1372.

${ }^{71}$ Suñer, $D S C, 26$ de abril de 1869, p.1360.

72 Figueras, DSC, 6 de abril de 1869, p. 874. 
"Protegida por el Estado, influirá sobre él y se le impondrá como se le ha impuesto siempre, y querrá a toda costa que las reglas de su moral sean las que prevalezcan [...] He aquí por qué nosotros, más lógicos, pedimos la completa separación e independencia, no sólo de la Iglesia católica, sino de todas las Iglesias"73.

Para este diputado todas las religiones intentarán imponer su libro sagrado dentro de los Códigos legales de los países donde se asientan dado que consideran "que el hombre es un ser insuficiente para conocer sus propias leyes morales y un ser más insuficiente para aplicarlas"74.

Para el diputado Garrido, la protección de una religión por parte del Estado conduciría a la degradación de la religión como le había ocurrido a la Iglesia católica: "Toda religión protegida, o por mejor decir, toda religión, toda teocracia, todo sacerdocio privilegiado, se degrada, se corrompe, se hace ignorante y pierde todas las condiciones morales..."75. Degradación que para Castelar no sólo afectaría al clero sino también al pueblo practicante ${ }^{76}$.

\section{LA DISPUTA ENTRE TOLERANCIA E INTOLERANCIA RELIGIOSAS}

La tolerancia no debe contemplarse sin más como el antecedente de la libertad religiosa: las raíces de ambas son diferentes. Como concepto histórico, es dinámico y sometido a variadas interpretaciones en función del contexto de discusión. Así quedó patente durante el debate sobre la libertad de cultos.

La cuestión sobre tolerancia/intolerancia se planteó de nuevo de forma dicotómica: para los liberales de las tres tendencias presentes en las Cortes, así como para los republicanos, la tolerancia exigia aprobar la libertad de cultos, mientras que la intolerancia se identificaba con el exclusivismo religioso. Para los clérigos que intervinieron en los debates de aquel Parlamento en cambio, la tolerancia de la Iglesia habría sido una constante en su historia, por lo que no sería necesaria la libertad de cultos.

Para defender la protección de la Iglesia católica actual recogida en los artículos, el Gobierno, además de reivindicar el pasado liberal de la Iglesia primitiva, como hemos visto, introdujo el relativismo histórico en cuanto al concepto de intolerancia. De hecho, la tolerancia habría nacido del "progreso general de la civilización y de la blandura y suavidad de las costumbres que han venido con la civilización misma"77: todas las religiones en su pasado habrian sido intolerantes. Por ello, para estos diputados el permitir la libertad de cultos sería un sintoma de progreso.

La posición de los republicanos es más compleja. Por una parte, los católicos necesitarán salvar la religión, que no la institución eclesiástica, y para ello recurrirán a los mismos argumentos ya comentados de considerar que la Iglesia primitiva y medieval fue tolerante (al permitir la coexistencia de las tres religiones); esta situación habría cambiado al corromperse la Iglesia por exceso de

\footnotetext{
73 Pi y Margall, DSC, 3 de mayo de 1869, p. 1570.

74 Pi y Margall, DSC, 24 de marzo de 1869, p. 704.

75 Garrido, DSC, 4 de mayo de 1869, p. 1604.

76 Castelar, DSC, 7 de abril de 1869, p. 901.

77 Valera, DSC, 29 de abril de 1869, p. 1477.
} 
poder: "Nace tolerante y se hace intolerante [...] (Era tolerante) cuando la Iglesia era dominada, y sin embargo de proclamar la intolerancia cuando es dominadora, se vuelve intolerante y comete los mayores horrores que se han cometido en el mundo"78.

Por otra parte, los republicanos aplicarán el término intolerante no sólo a los neocatólicos ${ }^{79}$, sino también a los liberales moderados ${ }^{80}$ por no atreverse a llevar a las últimas consecuencias la libertad de cultos: serian intolerantes pues no dejaban pensar a cada uno por sí mismo ${ }^{81}$.

En términos completamente diferentes se plantearán los carlistas y los clérigos, el concepto de tolerancia. “¿Si en España todos son católicos donde está la intolerancia?" se preguntarán desde las páginas de El Pensamiento Español ${ }^{82}$. El que no es católico "es porque no profesa religión alguna, y éstos, ¿no tienen la libertad que necesitan?"83. Puesto que existe la tolerancia necesaria a las características religiosas del país, ¿qué necesidad habria, se preguntará el Obispo de Santiago, de romper la unidad católica? Diferente sería si en España coexistiesen ya muchas religiones como en otros países, entre ellos Francia: en ese caso podría considerarse la libertad de cultos ${ }^{84}$. Para algún diputado, como Ochoa, la existencia de tolerancia (que permitiría el culto privado pero no el público) haría innecesaria la libertad de cultos. Dos serían, así pues, los motivos para no establecerla: España era toda ella católica (los españoles que no lo fuesen debía colegirse que no profesaban religión alguna) y a los extranjeros se les permitía el culto privado. Por ello para Ochoa

\begin{abstract}
"Basta que se consigne el hecho de que la religión católica apostólica romana es la religión de la Nación española y con que no se moleste ni perturbe a esos individuos [...] no se puede perseguir a ningún español que quiera dar a su modo culto a Dios en el seno de su casa; no se puede perseguir a ningún español que, encerrado en su hogar, levante su corazón a Dios, con su familia, y le adore en la forma que lo creyese conveniente, y no se perseguiría con mi enmienda a ningún español"85.
\end{abstract}

¿Era la religión católica intolerante? Manterola distinguía entre intolerancia contra el error y tolerancia contra quien yerre: "una cosa es la intolerancia con las doctrinas erróneas, la intolerancia que está en la naturaleza de las cosas, y otra la tolerancia con las personas que tienen la desgracia de errar"86. Ochoa

78 García Ruiz, DSC, 26 abril de 1869, p. 1364.

79 Neocatólicos es el nombre, con connotaciones peyorativas, que dieron la mayor parte de liberales, demócratas y republicanos, a un movimiento politico e ideológico de mediados y finales del siglo XIX, de confesionalidad católica, que pretendió superar la identificación del clero con el carlismo, pero que no siempre consiguió, y que intervino activamente en la vida política con una mayor o menor proximidad al tradicionalismo, según la coyuntura política.

80 El partido liberal moderado no obtuvo representación parlamentaria en las elecciones a las Cortes constituyentes y muchos de sus miembros se integrarán en la Unión Liberal.

81 "Comentario", La Igualdad, 29 de abril de 1869.

82 "La Tiranía y el despotismo en Religión", El Pensamiento, 29 de marzo de 1869.

83 “A las Cortes Constituyentes”, El Pensamiento, 6 de abril de 1869.

84 García Cuesta, DSC, 27 de abril de 1869, p. 1409.

85 Ochoa, DSC, 29 de abril de 1869, p. 1451.

86 Manterola, DSC, 27 de abril de 1869, p. 1397. 
introducirá, como el mundo liberal, la idea del relativismo para juzgar la intolerancia pero con un matiz: fue el poder civil, el intolerante, pero se debe de comprender dadas las circunstancias históricas ${ }^{87}$.

\title{
VII. CONSECUENCIAS DE LA LIBERTAD RELIGIOSA
}

En una interpretación apocaliptica, la coexistencia de varias religiones traería, a juicio de carlistas y clérigos afines, el caos y el desorden total de la sociedad y del Estado, pudiendo llegar a provocar su caída:

“¿[...] cómo vais a hacer que se perpetúe el Estado, el edificio que sobre esa base habiase levantado? Yo encuentro perfectamente lógico [...] que el hombre que deje de temer a Dios, se emancipe ya de toda autoridad humana [...] (y se rebele) contra toda autoridad, contra todo orden, contra toda superioridad"88.

Para el diputado Ochoa, incluso, detrás de la voluntad de establecer la libertad de cultos en España, existiría una conspiración orquestada por Inglaterra con vistas a retener Gibraltar ${ }^{89}$.

Para todos ellos, el establecer la libertad de cultos supondría un retroceso en la senda del progreso y, más grave todavía, la destrucción del catolicismo, disfrazada de tolerancia, de deberes internacionales o de intereses comerciales. Esta libertad supondría crear una situación de desigualdad negativa para el catolicismo frente a las otras religiones, además de abrir la "veda" contra los católicos. Particularmente relevante es la interpretación o traducción que hacen desde las páginas de El Pensamiento (artículo firmado F.B.S.) del significado de los artículos 20 y 21 :

\begin{abstract}
"Art. 20. Los Gobiernos liberales se reservan el derecho de perseguir más o menos embozadamente la religión católica, y de impedir por cuantos medios pongan a su alcance el protectorado y el regalismo al libre y legítimo desarrollo de sus instituciones. Art. 21. Cualquier extranjero tendrá derecho a predicar en España toda clase de doctrinas opuestas al dogma católico, y a levantar libremente templos de todas las religiones, hiriendo el sentimiento católico de los españoles, y contrariando su voluntad, sin más limitación que las reglas universales de la moral y del derecho, tales como los reglamentos de policía urbana que dictarán los ayuntamientos populares. También se reconoce el mismo derecho de escarnecer la Religión católica a los pocos españoles que si no son católicos, en cambio no tienen religión alguna [...] Los enemigos de tu religión podrán levantar libremente frente de tus iglesias capillas evangélicas, mezquitas y sinagogas, porque el ejercicio de sus falsos cultos les queda garantizado sin más limitaciones que las de las reglas universales de la moral y del derecho"90.
\end{abstract}

El Protestantismo, a pesar de su bajo grado de difusión a la altura de $1869^{91}$, será objeto de una dura crítica por parte de carlistas y clérigos, como otro

87 Ochoa, DSC, 29 de abril de 1869, p. 1450.

88 Manterola, DSC, 26 de abril de 1869, p. 1383.

89 Ochoa, DSC, 29 de abril de 1869, p. 1453.

90 "La verdad desnuda", El Pensamiento, 5 de abril de 1869. En cursiva en el texto original.

91 Con respecto a la situación del protestantismo en España en los momentos del debate parlamentario, haremos una brevísima mención, pues entrar en un análisis detallado requeriría 
argumento más para defender la unidad católica de España. Manterola destacará su grado de intolerancia a lo largo de los siglos ${ }^{92}$ y Ochoa el haber sido la fuente de todas las doctrinas negativas del siglo ("doctrinas que son una especie de degeneración del protestantismo, que eso y no otra cosa son el regalismo, el jansenismo, el liberalismo, el racionalismo"), al querer destruir el principio de autoridad y sustituirlo con el principio del criterio individual ${ }^{93}$. Aunque para los Obispos de Málaga y de Santiago, afortunadamente, a esas alturas del siglo, el Protestantismo estaba en total decadencia: “¿Que es hoy el protestantismo? Notadlo bien, señores diputados, es un cadáver, y un cadáver en putrefacción" 94 .

Sobre los ataques que sufrian o sufririan los católicos a manos de los protestantes, se extenderán los periódicos y los diputados. Así, Monescillo, refiriéndose a la supuesta entrada de protestantes en la Catedral de Sevilla repartiendo libros y papeles o durante una novena en un pueblo, afirmó: "insultaron a los santos, trataron de abatir las imágenes y dirigieron insultos ¡triste es decirlo! a Jesús sacramentado [...] ¿No veis, señores diputados, que aquí no se proclama la libertad de cultos, que esos hombres no piden la libertad de cultos, que piden la libertad de agresión?"95. Por ello no es de extrañar que el Obispo de Ávila en una circular a los sacerdotes de su diócesis autorizase quemar cuanto libro o folleto protestante encontrase, pues consentir la difusión del Protestantismo sería admitir la corrupción de los jóvenes, conducirlos al ateísmo e introducir la discordia entre las familias ${ }^{96}$. También la revista La Cruz recogía la lista de (supuestos) agravios sufridos por sacerdotes de diferentes localidades, que habrian tenido que huir de sus parroquias. Esta revista describia una situación de caos total llegando a afirmar “¿Cuando viene el diluvio?”97 Es tan grave la situación descrita por la prensa neocatólica que hasta llegan a plantearse la posibilidad de una guerra religiosa en España "si llega a implantarse en nuestro suelo el fanatismo protestante, que siempre ha ido acompañado de

la realización de otro estudio. Tal y como analizaba Antonio Orozco en su estudio sobre el protestantismo en Cádiz, la libertad de cultos obedeció más a una decisión política que a la existencia de un ambiente general de tolerancia religiosa (de aquí la prohibición en Cádiz de un cortejo fúnebre hacia el cementerio inglés en julio de 1869 o la denegación en 1870 de enterramientos en el cementerio municipal) (Antonio Orozco Guerrero, "La aplicación de la libertad religiosa en Cádiz durante el Sexenio Democrático en relación con los protestantes (18681874)", Espacio, Tiempo y Forma, Serie V, Historia Contemporánea, 24 (2012), pp. 267-289). En este mismo sentido se expresaba La Igualdad al mostrar el grado de incumplimiento de los artículos de la Constitución y la diferente actitud con respecto a los mismos del organismo público implicado en concreto: por ejemplo, menciona la negativa del Gobierno a admitir la decisión del Ayuntamiento de Madrid de no realizar función religiosa durante la celebración del 2 de Mayo (La Igualdad, 30 de abril de 1869).

92 Manterola, DSC, 12 de abril de 1869, p. 980; García Cuesta, DSC, 27 de abril de 1869, p. 1411.

93 Ochoa, DSC, 29 de abril de 1869, p. 1452.

94 “A las Cortes Constituyentes”, El Pensamiento, 6 de abril de 1869.

95 "Cortes Constituyentes", El Pensamiento, 15 de abril de 1869.

96 La Cruz, revista religiosa de España y demás países católicos dedicada a María Santísima, Tomo Primero, imprenta la Esperanza, Madrid, 1869, p. 467.

97 Ibidem, p. 735. 
horribles contiendas"98. Por ello no dudarán en llamar a la acción a los católicos: "Como católicos y como españoles, si estimamos en algo la religión de nuestros mayores y la patria en que hemos nacido, todos estamos en el imprescindible deber de hacer algo en defensa de tan sagrados objetos"99.

Los liberales de la coalición gubernamental dejarán constancia de la radicalización del elemento clerical unido al carlista. Así, La Iberia reproducirá la carta de un lector de Corella en la que se afirmaba que en la iglesia, así como en alguna tapia del pueblo, habían aparecido pintadas en contra de los liberales, en favor de la religión y de Carlos como rey: "Que viva la religión. Viva la Virgen María; Que mueran Prim y Topete con toda su compañia. Queridos carlistas, a las armas, a defender nuestra religión; a poner en el trono a Carlos VII y no dejar un liberal con vida" 100 .

La Igualdad destacará en numerosos artículos los llamamientos de los neocatólicos a funciones de desagravio por las pretendidas ofensas sufridas durante los debates de los artículos constitucionales, y el grado de violencia contenidas en ellos. Para los republicanos, sin embargo, el pueblo español estaba imbuido de principios de libertad, imagen totalmente opuesta a la que difundirán los neocatólicos. Pero el enfrentamiento entre ambas posturas era ya claramente evidente:

\begin{abstract}
"Los neos concitan los ánimos a pretexto de desagravios. Con sus excitaciones pretenden provocar la guerra civil. Inflaman el fanatismo invocando a Dios y la Virgen que suponen ultrajados. Esto manifiesta que están dispuestos a apelar a la lucha, para cuyo intento preparan el camino. Creemos que pronto, muy pronto, su descarado frenesí se traducirá en hechos [...] No olviden que el pueblo vive con la libertad y por la libertad, y que el primer conato puede ser castigado como justa represalia. Abran los ojos no dejándose arrastrar por su insolente venalidad. Terminen esas farsas indignas que es temible, que produzcan graves, gravísimos conflictos" ${ }^{101}$.
\end{abstract}

\title{
VIII. CONCLUSIÓN
}

Tal y como hemos visto, el concepto de libertad de cultos implicó, para los unionistas liberales, liberales progresistas, demócratas y republicanos, uno más de los derechos individuales del hombre equiparable a la libertad de pensamiento. Para los republicanos, en particular, la libertad de pensamiento era imprescindible para que existiese una libertad de cultos. La libertad de conciencia, tolerada por el clero, pues no implicaba culto público de otras religiones, no era para el resto de los diputados elemento suficiente para poder hablar de libertad de cultos. Tolerancia para ellos no podia significar libertad de cultos. En función del planteamiento teórico que realizarán de esta libertad, así los diferentes diputados desarrollarán la plasmación de la misma en la Constitución. Evidentemente, la libertad de cultos estaba estrechamente unida al

\footnotetext{
98 “Comentario", El Pensamiento, 28 de abril de 1869.

99 "Los macabeos", El Pensamiento, 30 de abril de 1869.

100 "Carta de un lector", La Iberia, 22 de abril de 1869.

101 “Comentario", La Igualdad, 5 de mayo de 1869.
} 
concepto de religión y de moral que tenían los diputados y publicistas, así como a los conceptos de tolerancia e intolerancia.

Las medidas anticlericales que se tomaron en este periodo fueron llevadas a cabo por diputados creyentes, la mayor parte de los cuales no puso en cuestión el dogma católico. Su deseo era reformar la institución eclesiástica. Y esto se tenía que manifestar al dotar de contenido a los diferentes conceptos que hemos analizado. Hasta las fechas consideradas en este estudio, el sustrato común subyacente seguía siendo el creyente: la religión seguía considerándose un elemento fundamental para la vida de los hombres y de las sociedades. Es cierto que se van a dar dos tipos de acercamiento a la religión, uno más basado en la fe y otro más en la razón; en muchos casos en una mezcla de ambos. Como ya en los inicios de siglo el concepto de moral universal empezó a cobrar fuerza, en estos momentos tendrá mayor importancia al sustituir en algunos casos a la moral católica y ser la base para los defensores de posturas ateas o agnósticas. La moral universal serviria de contrapeso a los posibles desmanes sociales y sería necesaria en el caso de supresión de la influencia eclesiástica en la sociedad.

Podemos considerar que en las Constituyentes de 1869 comienza en España el debate sobre la libertad de cultos que dura hasta hoy día. De hecho se plantearon muchas cuestiones y muchas argumentaciones vigentes todavía en nuestro presente. Pero, a la altura de 1869, el clima para el asentamiento en España de otras religiones en condiciones de igualdad con la católica, no estaba maduro.

Enviado el (Submission Date): 07/03/2017

Aceptado el (Acceptance Date): 12/05/2017 